\title{
Por entre as tardes e os efeitos dos encontros com Margueritte ou dos descaminhos de uma ethopoiesis de si
}

\section{For between afternoons and the effects of meetings with Margueritte or misplaced of an ethopoiesis}

https://doi.org/10.34112/2317-0972a2018v36n73p6g-85

Rosimeri de Oliveira Dias ${ }^{1}$

Maria Elizabeth Barros de Barros ${ }^{2}$

RESUMO: Este trabalho é feito por meio de uma aproximação ética, estética e política entre a formulação foucaultiana de escrita de si, e o filme "Minhas tardes com Margueritte", de Jean Becker. Aposta na tessitura de bons encontros, para problematizar uma prática de constituição de um sujeito ético no presente. Encontros são tomados, conforme propõe Gilles Deleuze, como o que pode fazer vibrar e revigorar a força de um acontecimento. $\mathrm{O}$ trabalho é dividido em dois momentos: amizade e seus efeitos ethopoiéticos; e práticas de si e seus entrelaçamentos com cinema e diferença. A força de um bom encontro é revigorada quando ela é posta numa perspectiva que desloca os pontos de vista dos personagens do filme, fazendo com que as imagens movimento e tempo mostrem feituras, apostando na força alegre de uma prática de si, para poder diferir e inventar modos outros de viver. Palavras chave: Escrita de si; acontecimento; ética.

ABSTRACT: This work is based on an ethical, aesthetic and political approach between Michel Foucault's writing the self and Jean Becker's “My Afternoons with Margueritte”. We have focused on the tessitura of good encounters, in order to problematize a practice of the constitution of an ethical subject in the present. The encounters are taken, as proposed

1. Universidade do Estado do Rio de Janeiro, Rio de Janeiro, RJ, Brasil.

2. Universidade Federal do Espírito Santo, Vitória, ES, Brasil. 
Por entre as tardes e os efeitos dos encontros com Margueritte ou dos descaminhos...

by Gilles Deleuze, as situations that can make the force of an event vibrate and invigorate. The work is divided into two moments: friendship and its ethopoietic effects; and practices of the self and how they interwine with cinema and difference. Such moments show that the strength of a good encounter is re-invigorated when it is understood in a perspective that shifts the points of view of the characters of the film, making the movement-images and time-images show feats and the joyful force of a practice of the self, so as to differ and create other ways of living.

KeYwords: Self-writing; event; ethics.

Foi um encontro discreto do afeto com o amor. Ela não tinha outro teto. Tinha nome de flor. Vivia cercada de palavras. Adjetivos, substantivos, verbos e advérbios. Alguns chegam sem jeito. Ela chegou com doçura. Quebrou minha armadura, e se alojou no meu peito. Nas histórias de amor não há apenas amor. Nunca dissemos... <eu te amo>. No entanto, nos amamos.

Não é uma história comum. Ela leu pra mim num banco de jardim. Era frágil como uma pomba sentada àquela sombra. Cercada de palavras de nomes comuns como eu. Me deu muitos livros que me tornaram mais vivo. Não morra agora, espere um pouco. Não é hora doce senhora, me dê um pouco mais ainda, um pouco mais da sua vida. Espere...histórias de amor não há apenas amor. Nunca dissemos 'eu te amo'. No entanto, nos amamos.

(BECKER, 2010)

Imagine a cena. Numa praça pública, por volta do final do século passado, um homem de meia-idade conversa com pombos, observado por uma senhora idosa. A Senhora, Margueritte, pede para que Sr. Germain diga detalhadamente os nomes dos pombos da praça. Cena que, no decorrer do filme, Minhas tardes com Margueritte, afirma os encontros regulares entre-dois. Na película, Germain, um tanto hesitante, senta-se ao lado de Margueritte, que, experiente com livros, abre um e inicia sua leitura em voz alta...

- Pronto!

- Terminou?

- Sim. Nós lemos A peste em dez dias. Exceto algumas passagens.

- Você leu.

- Não pense assim, Germain. Você é um excelente leitor. Ler é também escutar.

- Escutar? 
- Veja as crianças, quando as ensinamos a ler. Lemos para elas em voz alta. Se lemos bem e elas escutam bem, querem sempre mais. Depois, têm necessidade disso.

- Ficam viciadas, como numa droga. Nunca usei drogas, mas também nunca usei livros.

- Éseu.

- Não...

- Desta vez, aceite. Sim, eu insisto! Pronto. Neste mundo, passamos coisas adiante. Estou lhe passando um livro. Marquei os trechos que escolhemos para ler.

- Muito obrigado.

- Não vou dizer "de nada". Porque isso é alguma coisa. Posso compartilhar com você alguns textos que eu amo. Gostaria disso?

- Com esse olhar, devia enlouquecer os homens. "Gostaria disso"?

- Até logo, Germain.

- Até logo, Margueritte.

Em seguida, Margueritte caminha observada por Germain... que, em imagem movimento, toma um banho e tenta dormir, mas acorda, no meio da noite, para ler A peste. Reler, escutar, escrever - e vemos um filme que liga um homem sensível ao cotidiano que o cerca, entrelaçando-o com pessoas, com situações, com a vida marcada do menino "dito" problema, que se torna um adulto.

É com esta cena que abrimos nossa proposta de problematizar um bom encontro, que aqui será feito por meio de uma aproximação entre a noção de escrita de si (FOUCAULT, 2006a) e o filme Minhas tardes com Margueritte (BECKER, 2010). Uma aposta na tessitura de bons encontros para problematizar uma prática de constituição de um sujeito ético no presente. A escrita de si trata de uma prática filosófica do início de nossa era, destinada à formação do sujeito. Mas, antes de seguir, destacamos que nossa opção é pelas misturas de gestos intensivos e pequenos, pois estes nos forçam a provocar e a produzir encontros pela vida afora.

Gilles Deleuze nos diz que um encontro propicia um conjunto de sons, gestos, ideias pulsantes, atenção extrema, "risos e sorrisos que se sentem como "perigosos no exato instante em que se experiencia a ternura"(DELEUZE; PARNET, 2004, p. 22), para que seja possível atuar por potência positiva e afirmativa. Algo próximo de um duplo-roubo, um espaço-tempo que se posiciona, entre-dois, em uma micropolítica negociada, pois os ritmos são distintos, e há possíveis para forjar agenciamentos coletivos de enunciação,"encontrar, roubar, em vez de resolver, reconhecer e julgar. Porque o reconhecimento é o contrário de um encontro.” (p. 19). 
Por entre as tardes e os efeitos dos encontros com Margueritte ou dos descaminhos...

Encontro como algo próximo do que é possível ver em Minhas tardes com Margueritte. Um encontro efetivo, de uma autêntica conexão entre-dois, que afirma o imprevisível ou o inesperado, movendo-se em um chão que ele não domina. Um filme delicado, que mostra um bom encontro e deliciosas conversas. É o que vemos na encarnação de seus personagens: Germain e Margueritte. Eles não eram amigos de longa data. Conheceram-se entre tardes no jardim. Contando pombos e os denominando... sim, os pombos possuíam nomes! Um encontro que talvez pudesse vigorar a força de um acontecimento. $\mathrm{O}$ que é um encontro que vigora a força de um acontecimento? Talvez, porque Germain necessitasse da amizade que pudesse constituir uma ligação singular e potente, de diferir do que se constituiu. Tardes por entre pombos e leituras, por entre encontros e conversas geracionais, tecidos entre um homem, adulto, e uma mulher, idosa. Tardes por entre escutas, leituras e conversas, em que depois se sentiam impregnados com a potência da alegria, como se eles tivessem se presenteado com o encontro, que se faz vibrar em outros territórios. Essa sensação de alegria impregnada chegou a tal exaltação que, no dia em que Germain ganhou de presente um dicionário, a alegria impulsionou outros movimentos, outros tempos... entrelaces e pulsações que reverberam nos dias, nas manhãs...

O dicionário comparece em um desses encontros, tocando direto em modos e fazeres escassos na vida de Germain. Dispositivo (DELEUZE, 2016) movente, que forja uma multiplicidade virtual do encontro entre-dois - Germain e Margueritte -, envolvendo o cuidado de si e do outro. Como num novelo multilinear e colorido, o dicionário-dispositivo toca em planos sensíveis e racionais, que fazem emergir práticas de si nas manhãs e nas noites de Germain. Na solidão de Germain em seu trailer, na volta de tais encontros, as práticas do uso do dicionário eram grandes e áridas. Germain abre, procura e não encontra. Necessitava ampliar o grau de suportabilidade para aquela experiência! Por isso, dá um passo atrás, devolve o dicionário a Margueritte. Mas, mesmo devolvendo-o, o dispositivo reverbera e inventa outras linhas, ganhando movimento e tempo enquanto Germain ensaia para ler e se encontrar com Margueritte. Sim, os efeitos dos encontros e das conversas ganham formas outras, atravessando a vida de ambos, constituindo-as, inventando-as. Com isso, é possível dizer que o que acontecia dava forma a uma amizade sincera, que deseja a sinceridade pura, pautada na confiança ${ }^{3}$. Perguntamos, com Passetti (2003,

3. Confiança é um entrelaçamento de engajamento e indeterminação. É experiencia compartilhada que amplia a potência de agir. Implica forças de heterogeneização, que engendra um novo tipo de relação que não é pilotada por um desejo de completude e de eternidade, nem implica "anestesia aos efeitos das misturas do 
p. 15): "será mesmo a amizade a melhor das coisas que levamos da vida? Podemos responder brevemente dizendo que nada permanece com tanto vigor, dentre as diferentes formas de relacionamentos por nós estabelecidos como a amizade". Na tessitura da amizade, entre-dois, o que move Germain entre um trailer, a vida, as leituras, as tardes, os pombos, as lembranças que ganham imagens e movimentos em pequenos gestos de fazer, de cada tarde com Margueritte, um acontecimento?

Deleuze (2003, p. 152) afirma que "o brilho, o esplendor do acontecimento, é o sentido. $\mathrm{O}$ acontecimento não é o que acontece (acidente), ele é no que acontece o puro expresso que nos dá sinal e nos espera”. Quais seriam os operadores de um sentido, um acontecimento? Em Zourabichvili (2016) há a ligação estreita entre sentir e pensar a diferença pela força do fora, pelo que faz vibrar, intensivamente, seus operadores: pensamento e seu fora; encontro, signo e afeto; imanência; tempo e implicação; e devir. Operadores que dão a ver o que nos força a entrar em uma trama de pensamento comunicacional ancorada na exterioridade das relações da vida. Essas relações envolvem um sentir dimensionado como poder de afetar e ser afetado pelo fora ${ }^{4}$. São afetos que forçam o pensar a se envolver com a invenção de conceitos acontecimentais. Para tanto, é preciso estar atento ao alcance prático desse jogo de sobrevoos em superfícies sensíveis, e também à experiência de se sentir implicado com a diferença que nos coloca em movimento, mas que somente ele pode apreender. Por isso, talvez, é possível dizer que o acontecimento do encontro entre Germain e Margueritte implica um grau ampliado de abertura do sensível às ressonâncias de encontros vitais. Um cuidado que se ampara na experiência dos encontros intensivos, e com isso assume o desafio de afirmar o acaso.

$\mathrm{Na}$ cena da transferência de Margueritte para outro Asilo, emergem imagens e movimentos em uma bela estrada. Radiantes, sorridentes, se mostram - Margueritte

mundo, num faz de conta de uma existência estável, sem quedas" (ROLNIK, 1994, p. 8). Trata-se de um outro modo de subjetivação, um outro mundo neste mundo. "Amparar o outro na queda: não para evitar que caia, nem para que finja que a queda não existe ou tente anestesiar seus efeitos, mas sim para que possa entregar-se ao caos e dele extrair uma nova existência. Amparar o outro na queda é confiar nessa potência, é desejar que ela se manifeste. Essa confiança fortalece, no outro e em si mesmo, a coragem da entrega" (ROLNIK, 1994, p. 8).

4. Fora, para Deleuze, não se refere à exterioridade ou a uma realidade em conformidade com uma verdade. O fora afirma a diferença, a heterogênese e a multiplicidade, é um devir do pensamento que se faz criador na medida em que afirma o acaso e a multiplicidade. É tempestade de forças não estratificadas, é informe, espaço de singularidade onde as coisas não são ainda, pois é sempre abertura para um futuro, algo a se realizar. Trata-se de um real virtual. A realidade aí presente não está sob o domínio das formas e sim do indeterminado, imprevisível. As forças do fora indagam as verdades estabilizadas, fazendo-as tremer. 
Por entre as tardes e os efeitos dos encontros com Margueritte ou dos descaminhos...

e Germain - viajantes e leitores. Sim, foi um sequestro, um assalto da solidão asilar imposta a Margueritte, junto com um sanduíche dividido, preparando um ambiente perfeito para a amizade. Depois da viagem, eis os dois dentro de casa, de braços dados, conversando, lendo, cheios de amizade. Esta última frase traz as imagens virtuais forjadas com os movimentos do cinema. Um roubo, um duplo-roubo e o efeito do encontro com o cinema.

É curioso, com efeito, pois me parece evidente que a imagem não está no presente. No presente está aquilo que a imagem "representa”, mas não a própria imagem. A imagem mesma é um conjunto de entrelaces de tempo dos quais o presente apenas decorre, seja como múltiplo comum, seja como menor divisor. Os entrelaces de tempos nunca são vistos na percepção ordinária, mas sim na imagem, desde que esta seja criadora. Ela torna sensíveis, visíveis, os entrelaces de tempo irredutíveis do presente. (DELEUZE, 2016, p. 306)

E o que fica dessas imagens movimentos... Talvez, alguns entrelaces temporais do filme digam que os personagens queriam salvar um ao outro. Como se todos os problemas do sequestro asilar tivessem sido tocados, todas as possibilidades estudadas tanto por Germain, como por Margueritte. Nos viajantes vimos, desde a praça com os pombos e livros, apenas essa coisa que haviam procurado, sedentos até então, e enfim encontrado: uma amizade sincera, uma relação de confiança. Um modo, eles sabiam, e com que amargor sabiam, de enfrentar a solidão que um corpo tem.

Viajantes com livros e gestos, o encontro de Germain e Margueritte, nos mostram uma amizade aberta aos acontecimentos... Como se eles se espalhassem em longas tardes em truísmo que uma palavra esgota. Uma amizade insolúvel, construída por entre encontros, conversas e leituras... O que não bastava para encher as tardes, sobretudo porque elas reverberavam em manhãs e noites... Germain e Margueritte queriam tanto salvar um ao outro! A amizade entra como uma matéria-movimento de um cuidado de si e do outro.

Amizades e seus efeitos ethopoíticos: encontros e os SENSÍveis QUe TOCAM Germain E MARgueritte

Um filme que toca na potência da filosofia antiga, a que existia nos idos do início de nossa era. Pois a filosofia antiga não é disciplina do conhecimento, não 
tinha a ver com a formulação de sistemas de pensamento, com a organização do pensamento formal, com conceitos complexos demais que visavam à modificação do caos da vida em uma organização linear. Não! Não era isso! Então, o que era a filosofia antiga? Hadot (2014, p. 262) diz que "a filosofia antiga exigia uma conversão radical na transformação da maneira de viver. Um exercício tanto para alcançar a sabedoria, como para poder ser diferentemente".

A filosofia antiga era para ser vivida, para ser praticada, era para ser experienciada. O que estava em jogo nas escolas filosóficas não era a transmissão do conhecimento "puro". Os filósofos antigos buscavam conduzir os jovens, os discípulos para a conquista de uma maestria da "Arte de viver". Quando falamos em filosofia, aqui, nos referimos a essa filosofia como arte de viver. Foucault (1994) nos diz que não se pode aprender a arte de viver sem a askesis, que é entendida como treino de si por si mesmo. Isso é uma prática de si, um exercitar a si mesmo.

A filosofia é uma askesis, um exercício de si, um ensaio, uma experiência modificadora de si, para tomar a vida por si e poder transformá-la (FOUCAULT, 1994). Como fazer uma askesis? Preocupados na arte de viver, a atenção dos filósofos antigos volta-se para os hábitos, para a escrita, para a dieta, para os regimes de exercícios, para o uso dos prazeres sexuais ou etílicos... Como fazer, como modificar o modo de viver. Era esse o problema principal. E aí os filósofos foram direto ao ponto: mudando os hábitos, modificando os regimes, prestando atenção nas ações diárias. $\mathrm{O}$ como fazer implica uma ação. Por isso, a filosofia antiga é chamada de prática de si. Prática e conhecimento que visam em primeira e última instância a uma transformação do sujeito que conhece.

Foucault (2006a) nos diz que a escrita de si, como uma prática de si, é um contraveneno para um vaguear da vontade. A escrita de si é um dispositivo para enfrentar a multiplicidade, a pluralidade de imagens e as representações existentes no mundo exterior. A escrita de si possibilita a rememoração e permite que a vontade não se disperse. A vontade tem uma única e permanente meta. O que se deve sempre querer, segundo os gregos, é: o governo de si. Especialmente, aproximamo-nos mais com filósofos que nos forçam a pensar para seguirmos resistentes na vontade de se alegrar consigo mesmo.

"A escrita de si" (Foucault, 2006a) é uma prática que se inicia na Grécia no século IV a.C., com o uso dos hypomnêmatas, que são cadernos de notas que se tornaram comuns a todo um público culto. $\mathrm{O}$ que se anotava nos hypomnêmatas? Citações, fragmentos de obras lidas, exemplos e ações que se testemunharam e 
Por entre as tardes e os efeitos dos encontros com Margueritte ou dos descaminhos...

impressionaram. Pensamentos ouvidos em conversas ou em aulas ou que vieram à mente. Algo próximo de uma memória material das coisas lidas, ouvidas ou pensadas. Foucault nos diz que a escrita constitui uma "experiência e uma pedra de toque: revelando os movimentos do pensamento, ela dissipa a sombra interior onde se tecem as tramas dos inimigos" (2006a, p. 145). E ele completa (p. 147):

A escrita constitui uma etapa essencial no processo para o qual tende toda a askesis: ou seja, a elaboração dos discursos recebidos e reconhecidos como verdadeiros em princípios racionais de ação. Como elemento de treinamento de si, a escrita tem, para utilizar uma expressão que se encontra em Plutarco, uma função etopoiética: ela é a operadora da transformação da verdade em éthos.

É Foucault também quem nos definirá o que é um éthos: maneira de ser e de se conduzir, problematizando o tema da liberdade e da liberdade do indivíduo como um problema ético; que, para Foucault (2006b, p. 270-271), trata do sentido em que os gregos o entendiam, seu éthos visível para os outros. Seus hábitos, seu porte, seu modo de caminhar, sua calma em responder aos acontecimentos... A forma concreta da liberdade era seu modo de viver e de se conduzir, por isso eles - os gregos - problematizavam sua liberdade. Para que as práticas de liberdade tomem forma de um éthos, é necessário todo um trabalho de si sobre si mesmo, que implica

[...] relações complexas com os outros, uma vez que esse éthos da liberdade é também uma maneira de cuidar dos outros; [...]. O éthos também implica uma relação com os outros, já que o cuidado de si permite ocupar a cidade, na comunidade ou nas relações interindividuais o lugar conveniente - seja para exercer uma magistratura ou para manter relações de amizade. (FOUCAULT, 2006b, p. 270-271)

Como uma prática de si, os hypomnêmatas não são apenas um suporte para a memória. O exercício completo é ler, escrever, reler, conversar consigo, conversar com outros. As práticas de si - como a escrita de si - objetivam transformar o discurso recebido em ação, em modos de viver, em éthos. E, quando temos um acontecimento inesperado da vida, colocamos à prova esse ensaio. É nos momentos de enfrentamento do real que se deve ter à mão, isto é, marcados na alma, os princípios que ajudam o sujeito a dar uma resposta ética própria ao acontecimento. 
O fundamental para os filósofos antigos é que essa diversidade de discursos reunidos em hypomnêmatas, em anotações, em cartas, seja posteriormente subjetivada por meio da releitura e da meditação. $\mathrm{O}$ importante é que tais discursos possuam uma unidade. Não é uma reunião pura e simples de fragmentos de leitura ou de opiniões. É algo próximo de um canto coral. Há vozes plurais, agudas, graves, médias, femininas e masculinas. No coral, nenhuma voz individual pode, nela mesma, se distinguir; somente as vozes plurais se afirmam em coletivo. Vozes com suas singularidades, seus preceitos, mas convergindo em uma unidade (FOUCAULT, 2006a).

Com este exemplo do coral, dado por Sêneca (2014), podemos dizer que é esta unidade, marcada por singularizações, pois não é homogeneidade e sim polifônica, a grande obra de uma escrita de si. Imaginamos algo como se fosse um outro corpo escrito em nós. Um outro corpo que nos ampara, que nos aconselha e que nos impulsiona a agir. Um corpo voz que nos orienta nas decisões cotidianas. Próximo do que encontramos entre Margueritte e Germain: um encontro polifônico de sensíveis vozes, mediado pelas leituras e pelos encontros.

A constituição do gesto de escrever, da leitura e da releitura pode unificar fragmentos heterogêneos por meio da subjetivação do exercício da escrita pessoal. Nesses termos, a função de uma escrita de si é a da constituição, com todas as leituras e releituras, de um corpo. Mas Foucault nos chama a atenção para a necessidade de compreender que esse corpo não é de doutrina, mas sim um corpo concreto de gestos: "a escrita transforma a coisa vista ou ouvida em forças e em sangue"(FOUCAULT, 2006a, p. 152).

Os hypomnêmatas, como uma prática de si, um exercício de pensamento que faz da vida uma obra definida entre o pensar e o agir, tratando de fazer coincidir o olhar do outro e aquele que se lança sobre si mesmo, ao comparar suas ações cotidianas com as regras e as ações de uma técnica de vida. Um exercício de pensamento que não se refere a uma prática coercitiva, mas a uma prática de autoformação, acentuando os modos de ser e a maneira de se conduzir, ou seja, sua atitude, seu éthos.

$\mathrm{Na}$ escrita de si, o movimento do exercício, como uma experiência modificadora de si, volta-se para fora, para o mundo e a vida. O praticante está captando, selecionando, escrevendo, lendo, relendo; e incorporando, subjetivando; tornando seu pensamento, gestos, discursos, princípios, exemplos que estão fora de si para tornar quem se está sendo. A pergunta mais importante para os filósofos antigos é "como faço para viver como se deve?" Como nos formamos, como nos educamos, qual a instrução necessária... $\mathrm{Na}$ escrita de si estamos voltados para fora, para ver 
Por entre as tardes e os efeitos dos encontros com Margueritte ou dos descaminhos...

com admiração o outro, esse outro que pensou e realizou coisas admiráveis, que serve como exemplo para transformar em ação, produzindo uma coerência entre o que você diz e o que você faz, entre o pensar e o agir.

Práticas de si e SEUS ENTRELAÇAMENTOS COM CINEMA E COM DIFERENÇA

Talvez, no entrelaçamento cinema, filosofia antiga e diferença, seja possível dizer que Margueritte e Germain forjaram, com as leituras pelas tardes no jardim, uma prática de si. Quais as práticas produzidas pela leitura entre dois, propostas pelos encontros entre Margueritte e Germain? Quais as relações entre leitura e as artes da vida?

Michel Foucault, como já indicamos, destaca a importância dos exercícios ensaísticos que buscam, por meio da filosofia, um refinamento na arte de viver. Como fazer para viver como se deve? Talvez, trata-se de enfrentar um problema com o qual lidamos no dia a dia. Uma face da filosofia descolada da abstração e do transcendental, que possui seus percursos labirínticos. Mas essas trajetórias labirínticas não são para ser mapeadas, medidas e traduzidas em enunciados ou estruturas conceituais. Atravessar o labirinto das artes de viver significa aproximar-se de si mesmo e, eventualmente, desprender-se de si, a fim de inventar outras saídas e sentidos para uma existência que até então se encontrava perdida, olhando mapas e desprezando horizontes.

Para Foucault, o valor de um sujeito era avaliado segundo o seu éthos, a sua maneira de ser - que não era natural ou inata -, mas, sim, elaborada de forma estudiosa e modificada lenta e arduamente. Os gregos, como dissemos, reconheciam como bela existência aquela em que o sujeito consegue estabelecer uma coerência visível entre o que ele diz, o que ele pensa, o que faz e como se comporta frente aos outros ou às dificuldades da vida. Era essa obra esculpida, que seria admirada como uma verdadeira obra de arte.

No entrelaçar dos tempos moventes, o filme Minhas tardes com Margueritte circula em situações para pensar o presente: "Bravo! Que imbecil! Fala a mãe de Germain em um mercado de bairro, após a criança Germain ter quebrado um vidro de leite. Olhos pulsantes dizem a intensidade viva da relação mãe e filho: "E temos isto. Como, dá prejuízo e se suja. É só o que isto faz", diz a mãe. A imagem do passado se entrelaça com a do presente, e a cena seguinte é a de uma mão esculpindo um pedaço de madeira, simultaneamente à voz de Germain adulto: "Isto"... Como pode 
chamar alguém de "isto"? Nem um cão eu chamaria de "isto". Se eu tivesse um cão, o chamaria de ... cão. "Isto"...

Germain foi um típico "menino problema", como habitualmente se denomina nos espaços educacionais (ou escolas), e com diferenças em seus modos de funcionamento, tornou-se homem e cultivou a arte de esculpir pássaros... livres... Germain teve a ousadia de converter sua própria existência e cultivar gestos para fazer modo de vida livre, aproximando de uma maneira invulgar a experiência com os outros e consigo. Há em Germain uma conexão tensa entre seus gestos e sua vida singular, errante e solitária. Suas pichações e entalhos em madeiras, de início, e, depois dos encontros com Margueritte, as leituras podem ser pensadas como registros minuciosos de um ethos, na tentativa de tornar-se outro.

É no jardim que Germain encontra Margueritte. Um encontro simples e provocador, como os que abrem caminhos para ele se encontrar consigo mesmo, com os seus desejos, problemas, gostos e modos de ser. Mas esse encontro não foi dado somente pelas leituras dos livros, mas, sobretudo, pela vida cotidiana, pela atitude, pelos costumes, pela abertura de espaço-tempo do encontro com o outro. Um éthos entre eles. Uma amizade tecida pela ethopoiesis de ler, de escutare de se encontrar para conversar. A ação entre eles seria ética nesse sentido: o modo de viver e de ser livre para encontrar uma maneira de ser, de pensar e de agir singular. Não era apenas por meio das leituras de livros ou do conhecimento que Margueritte possuía, que se daria esse encontro. Ambos eram simples e honestos um com o outro no pensamento e na vida. Germain coloca sua atenção nos verdadeiros problemas que se apresentam para o homem. Isto é o seu regime alimentar, a busca por um clima e um local adequado para o desenvolvimento de si... um trailer no quintal da casa de sua mãe, em que ele cultiva sua horta, e pode se relacionar com sua mãe, em uma distância ótima para seguir sua vida. Germain pensa as coisas próximas e concretas. O que pode ser efetivamente alterado, mudado, transformado. Sua aposta é a de prestar atenção nas coisas próximas e pequenas do existir com carne, osso e desejo.

Vale retomar uma questão já colocada logo no início: o que em um encontro vigora a força de um acontecimento? Zourabichvili (2016, p. 150) nos diz que

algo só é experimentado, só consiste, no sentido forte, quando posto numa perspectiva que desloca os pontos de vista, fazendo com que eles se retomem desigualmente uns nos outros. Somos viventes, intensos e pensamos tão somente enquanto pelo menos algum outro pensa em nós. 
Por entre as tardes e os efeitos dos encontros com Margueritte ou dos descaminhos...

Próximo do que encontramos na cena do jardim:

Germain aguarda Margueritte e interpela uma mulher que se aproxima com um carrinho e duas crianças:

- Está ocupado.

- O quê?

- Ocupado.

- Como assim, ocupado?

- Que audácia!

- Bom dia, Sr. Chazes.

- Pode me chamar de Germain.

- Germain?

- Sim.

- Só vou chamá-lo assim se me chamar de Margueritte.

- Se insistir, não tenho escolha.

- Sim, eu insisto.

- Então, está bem.

- Me atrasei porque meu sobrinho e sua mulher chegaram da Bélgica. Chegaram sem avisar. Tiveram um problema de dinheiro.

- Você viu? Parece até que nós tínhamos um encontro marcado.

- Como um encontro amoroso.

- Humm... Parece bom o seu sanduíche.

- Quer um pedaço?

- Obrigada, almocei há pouco. É estranho ver um homem num jardim a esta hora. Você não tem emprego?

- Sim, tenho vários. Mas posso apertar o botão "pausa".

- Pensei em você na noite passada.

- Em mim? Porquê?

- Pensei em você e nos nossos pombos. Sabe, quando estamos escolhendo um livro, ficamos lendo trechos ao acaso. Acabei me deparando com uma frase... Agora não me lembro... Vou encontrá-la.

(Margueritte, sob o olhar atento de Germain, pega seus óculos, abre sua bolsa e saca um livro)

"Como imaginar, por exemplo, uma cidade sem pombos, sem árvores e sem jardins, onde não se encontra nem rufar de asas, nem farfalhar de folhas, um lugar neutro, em 
suma, onde a mudança das estações só é percebida no céu e a primavera se anuncia apenas na qualidade do ar e nos buquês de flores que os pequenos vendedores trazem dos subúrbios. Uma primavera que é vendida nos mercados."

- Você gostou?

- Sim, mas poderia... Começar tudo de novo, desta vez não tão rápido?

- Claro, com todo prazer.

E Margueritte repete a leitura, e antes de terminar é interrompida por Germain.

- Isso não poderia existir. Mas não é ruim, o seu livro. Como se chama?

- "A Peste". De Albert Camus.

- Albert! Como o meu avô!

- Posso emprestá-lo, se quiser.

- Não... Sabe, eu não leio muito...

Na cena seguinte, aparece Germain menino, lendo com lentidão e fragmentariamente o livro que lhe era solicitado. Por entre imagens e movimentos, o tempo presente se afirma como gestos estéticos de um homem que liga passado, presente e futuro... Imagem movimento e tempo para uma cena com Germain, já homem, e seus colegas de bar...

- É um burro, mesmo... (diz um dos personagens do bar)

A cena seguinte já mostra Germain trabalhando em seu canteiro, falando consigo...

- Aqueles babacas, sempre rindo de mim. Ler é complicado. Para você eu posso confessar

(se dirigindo ao seu gato). Sabe... Você lê uma palavra, a segunda, a terceira... você segue em frente, sublinhando com o dedo, onze, doze, até o ponto final. Aí você avançou um pouco. $O$ problema é que você quer juntar as palavras mas elas se embaralham. Como porcas e parafusos jogados numa caixa, entende? As pessoas que sabem, para elas éfácil. Como Margueritte. Ah! Se você visse aquela velhinha! Quarenta quilos, sempre bem arrumadinha. A cabeça cheia de prateleiras com livros, livros... E ela entende tudo!

Cenas entrelaçadas descontinuamente, que mostram a composição acontecimental da vida de Germain. Como vemos nas imagens das conversas entre Margueritte e Germain...

- Você é um bom homem, Germain. 
Por entre as tardes e os efeitos dos encontros com Margueritte ou dos descaminhos...

- Obrigada por estas maravilhas. (Refere-se Margueritte a uma cesta de legumes e verduras dadas por Germain). Mas, para carregá-las, preciso de uma carroça.

- Vou ajudá-la. Onde a senhora mora?

[...]

- Pessoalmente, gosto muito daquele lar de idosos. O ambiente é bom, a equipe é cuidadosa.

Porque, você sabe, a velhice é um fardo. Sobretudo para os outros. A vantagem da velhice é que, quando nos aborrecemos, sabemos que não será por muito tempo.

- Uma frase ficou na minha cabeça. É do livro que nós começamos. "Uivar como um cão sobre o túmulo de sua mãe".

- Tem certeza dessa frase?

- Sim, tenho certeza.

... Germain repete a frase de memória... enquanto Margueritte a procura no livro...

- Ah, aqui está! Você tinha razão. "Voltamos sempre para uivar sobre o túmulo de nossa mãe, como um cão abandonado".

- Isso mesmo...

- Germain, estou impressionada. Você tem uma excelente memória auditiva.

- Não, apenas me lembro das coisas que ouço.

... Margueritte sorri e recoloca seus óculos, continuando a leitura susurradamente...

- E eu? Também quero escutar.

- Desculpe, me distraí. "Não é bom ser tão amado numa idade tão tenra. Isso cria maus hábitos. Nós ansiamos, esperamos, criamos expectativas. Com o amor materno a vida nos faz, na aurora, uma promessa que não cumpre".

- Esse é o título. O título... "A promessa da Aurora". É porque, no início, a vida faz promessas que não pode cumprir.

- É exatamente isso. Existe o amor materno e depois... Depois, "cada vez que uma mulher toma você nos braços e o aperta junto ao peito, são apenas condolências. Voltamos sempre para uivar sobre o túmulo da nossa mãe, como um cão abandonado". Aí está. "Nunca mais, nunca mais aqueles braços adoráveis enlaçam o seu pescoço e aqueles lábios doces lhe falam de amor". Assim pensa o autor, Romain Gary, que adorava sua mãe.

- Por quê? Não é uma história inventada?

- Não, é a história da vida dele.

- E se tivesse sido o contrário?

- O contrário?

- Sim. Se ele não fosse amado pela mãe, o que teria acontecido? 
- Sei lá. Se uma criança não recebe amor durante a infância, precisa descobrir tudo depois, não?

- Não sei nada sobre isso. Não sei.

- Sua mãe está viva, Germain?

- Ah, está!

- Como ela tratava você, quando garoto?

- Não dava a mínima.

- E agora?

- Continua não dando a mínima. Me trata como um nada. É como se não existisse.

- É terrível, o que você diz. A indiferença é a pior coisa, ainda mais para uma mãe.

- Como diz Jojo, ela não leva jeito...

Um homem que pelo seu passado estava condenado ao dito lugar da diferença que atinge a todos nós. Mas seu modo de vida atrelado aos encontros com Margueritte nos faz ver um homem em transformação de si, que se encontra com a sua condição existencial, e amplia seu grau de suportabilidade para a leitura e uma vida atravessada por ela... Mas ele fala a Margueritte que não é fácil:

- É tarde demais para mim, sabe? Não precisa cortar a floresta da Amazônia para fazer dicionários que não ajudam aos idiotas. É como dar óculos para um míope. De repente, vemos tudo, todas as falhas e defeitos. Tentei aprender com você...mas dói muito. Era melhor antes, era tudo mais simples.

Olhando-o atentamente, Margueritte diz suavemente: Vou fazer o chá. Se retira do ambiente, mas continua falando...

- Quando você diz isso, também dói em mim.

Mas, naquele mesmo encontro, eles continuam... a leitura atravessa suas vidas, como uma pedra de toque, enlaçando singularidades e diferenças que os aproximam. Sim, um belo encontro! De confiança. De vida e de leitura. De cinema e de invenção. De um homem que não lê e se torna um leitor. De uma senhora sensível, delicada, com um homem dito rude, mas artista. Um escultor da vida, esculpindo pássaros e a sua própria vida. Ao cuidar de si ele relê, escuta e escreve sua própria vida, com suas diferenças, seu estilo de vida, seus amigos de bar:

- Não tem mais tempo para jogar com seus amigos? 
Por entre as tardes e os efeitos dos encontros com Margueritte ou dos descaminhos...

- O que está havendo, Germain? Não bebe mais, fala palavras que não entendemos. Quando isso vai acabar?

- É verdade, você mudou e preferimos o Germain antigo.

- Logo vai parar de trepar. Tenho pena da pobre Annette.

- Eu não trepo mais com Annette. Agora fazemos amor. Aprendo palavras novas e vocês ficam putos? Se não gostaram, vão à merda. E isso não é uma lítote...

Sentado no banco do jardim com o presente deixado por Margueritte, o dicionário, Germain fala os nomes dos pombos e tem a ideia do sequestro....um rapto para que os bons encontros e a amizade perdurem, para abrir flancos no acaso e criar um tempo que vagueia da dedicação de um para o outro... mas se afirma por um entre-dois, imagem e movimento do que se tem de um bom encontro. Contudo, e, para terminar como começamos, é bom repetir... "Foi um encontro discreto do afeto com o amor... entre um homem, uma mulher, livros, leituras, vidas... sempre apostando na força alegre de uma prática de si, para poder diferir e inventar modos outros de viver”.

\section{REFERÊNCIAS}

DELEUZE, G. Lógica do sentido. Trad. Luiz Roberto Salinas. São Paulo: Perspectiva, 2003. . Dois regimes de loucos: textos e entrevistas. Trad. Guilherme Ivo. São Paulo: Editora 34, 2016.

DELEUZE, G.; PARNET, C. Diálogos. Trad. José Gabriel Cunha. Lisboa: Relógio D’água, 2004. FOUCAULT, M. Escrita de si. In: Foucault, M. Ditos e escritos $V$ : ética, sexualidade, política.

Trad. Tradução de Elisa Monteiro e Inês Autran Dourado Barbosa. Rio de Janeiro: Forense Universitária, 2006a. p. I44-I62.

. Uma ética da existência. In: FOUCAULT, M. Ditos e escritos $V$ : ética, sexualidade,

política. Trad. Elisa Monteiro e Inês Autran Dourado Barbosa. Rio de Janeiro: Forense Universitária, 2006b. p.288-293.

. A hermenêutica do sujeito. Trad. Márcio Alves da Fonseca e Salma TannusMuchail. São

Paulo: Martins Fontes, 2004.

. História da sexualidade 2:0 uso dos prazeres. Trad. Maria Thereza da Costa Albuquerque. Rio de Janeiro: Graal, 1994.

HADOT, P. Exercícios espirituais e filosofia antiga. Trad. Flávio Fontenelle Loque e Loraine de Fátima Oliveira. São Paulo: É realizações Editora, 2014.

PASSETTI, E. Éticas dos amigos: invenções libertárias da vida. São Paulo: Imaginário, 2003. ROLNIK, S. Hal Hartley e a ética da confiança. In: Trafic. Révue de Cinéma, n. 12, p.104-114. P.O.L.,

Paris, outono, 1994.

SÊNECA, L. A. Cartas a Lucílio. Lisboa: Fundação Calouste Gulbenkian, 2014.

ZOURABICHVILI, F. Deleuze: uma filosofia do acontecimento. São Paulo: Editora 34, 2016. 
Filmografia

BECKER, J. Minhas tardes com Margueritte. Paris: Imovision, 2010. 122 min., som, cor.

\section{SOBRE AS AUTORAS}

Rosimeri de Oliveira Dias é graduada em Pedagogia (Universidade do Estado do Rio de Janeiro), tem Mestrado em Educação (Universidade do Estado do Rio de Janeiro) e Doutorado em Psicologia (Universidade Federal do Rio de Janeiro). É professora/pesquisadora da Universidade do Estado do Rio de Janeiro. Tem experiência na área de Educação, com pesquisas nos seguintes temas: estudos foucaultianos, políticas cognitivas, produção de subjetividade, experiência, estética da existência e formação inventiva de professores. É Procientista/UERJ e Jovem Cientista do Nosso Estado/FAPERJ.

E-mail: rosimeri.dias@uol.com.br.

Maria Elizabeth Barros de Barros é graduada em Psicologia (Universidade Federal do Rio de Janeiro), tem Mestrado em Psicologia Escolar (Universidade Gama Filho) e Doutorado em Educação Brasileira (Universidade Federal do Rio de Janeiro). É professora/pesquisadora da Universidade Federal do Espírito Santo. Tem experiência na área de Educação, Saúde Coletiva e Psicologia Institucional e do Trabalho, com pesquisa em saúde do trabalhador da Educação, com bolsa produtividade do CNPq nível 1.

E-mail: betebarros@uol.com.br.

Recebido em 27 de janeiro de 2018 e aprovado em 22 de março de 2018. 